\title{
HPLC Assay Method Development and Validation for Quantification of Capecitabine in Tablets and Forced Degradation Samples
}

\author{
MS BHATIA, JN RAUT, AC BARVE, PS PATIL, SD JADHAV
}

\begin{abstract}
A simple, rapid, accurate and stability indicating RP-HPLC method was developed for the determination of Capecitabine in pure and tablet dosage form. The mobile phase consisting of $0.1 \%$ aqcetic acid, methanol and acetonitrile in the ratio of 35:60:5 $v / v$. The Inertsil ODS (octadecyl silane), C18, 3V, $250 \mathrm{x}$ $4.6 \mathrm{~mm}, 5 \mu \mathrm{m}$ with UV detection $304 \mathrm{~nm}$ was used. The retention time was found to be 6.4 minutes. The method was statistically validated for accuracy, linearity, precision, robustness, specificity and range. The method was found linear over the concentration range of $50-150 \mu \mathrm{g} / \mathrm{ml}$. The recovery studies of dosage form were also carried out and analyzed; the $\%$ relative standard
\end{abstract}

deviation (RSD) from recovery studies was found to be within limits. The specificity of the method was ascertained by forced degradation studies by acid, alkali hydrolysis and oxidation. About $35 \%$ of drug is degraded in acidic medium and less than that in alkaline and oxidative conditions. Due to simplicity, rapidity and accuracy of the method, the method will be useful for routine analysis and checking purity of capecitabine tablet. The method further can be investigated for pharmacokinetic and biopharmaceutical analysis.

Keywords: Capecitabine, 5-fluorouracil, metastatic breast, colorectal cancer, RP-HPLC, ICH guidelines.
Manısh Sudesh BHATIA, Jivan N RAUT, Anuja C BARVE, Prachı S PATIL, Swapnil D JADHAV

Department Of Pharmaceutical Chemistry, Bharatı VIDYAPEETH COLLEGE Of Pharmacy, Kolhapur - 416013, INDIA.

Corresponding Author:

Manısh Sudesh BHATIA

e-mail: bhatiamanish1312@gmail.com

Revised / Düzeltme: 30.04 .2017
Submitted / Gönderilme: 15.03.2017

Accepted / Kabul: $\quad 04.05 .2017$

\section{INTRODUCTION}

Capecitabinehasthe chemical namepentyl [1-(3,4-dihydroxy5-methyl-tetrahydrofuran-2-yl)-5-fluoro-2-oxo- $1 \mathrm{H}$ pyrimidin-4-yl]aminomethanoate [1]. It is a white to almostwhite solid with a molecular formula of $\mathrm{C}_{15} \mathrm{H}_{22} \mathrm{FN}_{3} \mathrm{O}_{6}$ and a molecular weight of 359.3 (Fig. 1). Capecitabine tablets contain NLT $93.0 \%$ and NMT $105.0 \%$ of the labeled amount of Capecitabine [2]. Capecitabine is an orally-administered chemotherapeutic agent used in the treatment of metastatic breast and colorectal cancers. Capecitabine is a prodrug, that is enzymatically converted to 5-fluorouracil in the tumor, where it inhibits DNA synthesis and slows growth of tumor tissue. The activation of Capecitabine follows a pathway with three enzymatic steps and two intermediary metabolites, 5'-deoxy-5-fluorocytidine (5'-DFCR) and 5'-deoxy-5fluorouridine (5'-DFUR), to form 5 -fluorouracil [3]. The final step is the tumor-activated conversion to 5 -FU by TP, predominantly in malignant cells. This site-specific action may result in higher tumor site concentrations and lower systemic toxicity than that seen with intravenous use of 5-FU [4]. 
Capecitabine is administered orally. Absorption is rapid with peak plasma levels occurring in about 1.5 hours (compared to 2 hours for 5 -FU). Food decreases the rate of absorption of Capecitabine (60\% reduction in peak plasma concentration) and AUC by $35 \%$. Less than $60 \%$ of Capecitabine and its metabolites are bound to plasma protein. The elimination half-life of both Capecitabine and 5-FU is about 0.75 hours, with more than $70 \%$ of the administered dose recovered in urine, largely as the alanine metabolite of 5-FU [5]. The absolute bioavailability of Capecitabine is $42 \%$ with low interpatient variability [6].

The usual starting dose is $2,500 \mathrm{mg} / \mathrm{m}^{2} /$ day in two divided doses, 12 hours apart. One cycle includes two weeks of treatment followed by one week without treatment. Cycles can be repeated every three weeks [7].

There are many methods which were developed and validated for the determination of capecitabine from various formulations. In that the HPLC-UV, liquid chromatography - tandem mass spectroscopy and automatic pressure chemical ionization LC-MS/MS method for determination of capecitabine and its metabolites from human plasma, using $\mathrm{C}_{18}$ reversed phase column with formic acid solution (pH-3) : ethanol $(55: 45, v / v)$ as mobile phase, Atlantis dC18 column under gradient elution respectively which were validated according to the FDA guidelines [8-15]. Another liquid chromatography- tandem mass spectrometry method for determination of capecitabine in dried blood spot, separation was done on Phenomenex Gemini $\mathrm{C}_{18}$ column, isocratic condition for mobile phase as acetonitrile : 2 mmole ammonium formate $(80: 20, v / v)$ [16]. Reversed phase method was developed for capecitabine determination in bulk and pharmaceutical formulations where separation performed on Welchrom $\mathrm{C}_{18}$ column with isocratic mobile phase containing methanol: acetonitrile: water (50:30:20, $v / v)$ which was monitored at $245 \mathrm{~nm}$, method was validated according to ICH guidelines [17]. Spectrophotometric methods were developed for determination of capecitabine based on their oxidation and precipitation reactions, which was monitored by measuring absorbance of produced complexes [18]. HPLC method was developed for the simultaneous determination of capecitabine and its metabolites in mouse plasma, liver, human xenograft tumors with electrospray ionization and detected by mass spectrometry, this method was cross validated in human plasma and human tumor for clinical applications [19]. Hence there is need to develop simple, accurate, sensitive and selective method for quantification of capecitabine.

\section{MATERIALS AND METHODS}

\section{Chemicals and reagents}

A HPLC grade, acetic acid, acetonitrile, and methanol were procured from Merck Labs. Mumbai. Hydrochloric acid, sodium hydroxide and hydrogen peroxide were obtained from Merck Labs. Mumbai. Distilled water was obtained from Milli Q water system in laboratory. Capecitabine reference standard was obtained from Glenmark Pharmaceuticals Ltd., Sinnar. The marketed formulation of capecitabine was procured from local market.

\section{Instrumentation and chromatographic conditions}

An isocratic HPLC system of Schimadzu LC2010 UV detector having software LC solution was used for chromatographic analysis. The chromatographic conditions were optimized and these were as shown in Table 1.

\section{Solutions Preparation}

\section{Preparation of Mobile Phase}

A $0.1 \%$ solution of acetic acid is prepared by dissolving $1 \mathrm{ml}$ of glacial acetic acid in sufficient distilled water to produce $1000 \mathrm{ml}$. A mixture of $0.1 \%$ acetic acid, methanol and acetonitrile was prepared in the ratio of 35:60:5, $v / v / v$ and degassed by sonication for 30 minutes.

Table 1. Chromatographic conditions

\begin{tabular}{lc}
\hline Column & Inertsil ODS, $3 \mathrm{~V}, 250 \times 4.6 \mathrm{~mm}, 5 \mu \mathrm{m}, \mathrm{C} 18$ \\
Mobile Phase & $0.1 \%$ acetic acid, methanol and acetonitrile $35: 60: 5, v / v / v$ \\
Detector (Wavelength) & UV $250 \mathrm{~nm}$ \\
Flow rate & $1.0 \mathrm{ml} / \mathrm{min}$. \\
Column temperature & $40^{\circ} \mathrm{C}$ \\
Injection volume & $10 \mu \mathrm{l}$ \\
Run time & 10 minute \\
\hline
\end{tabular}




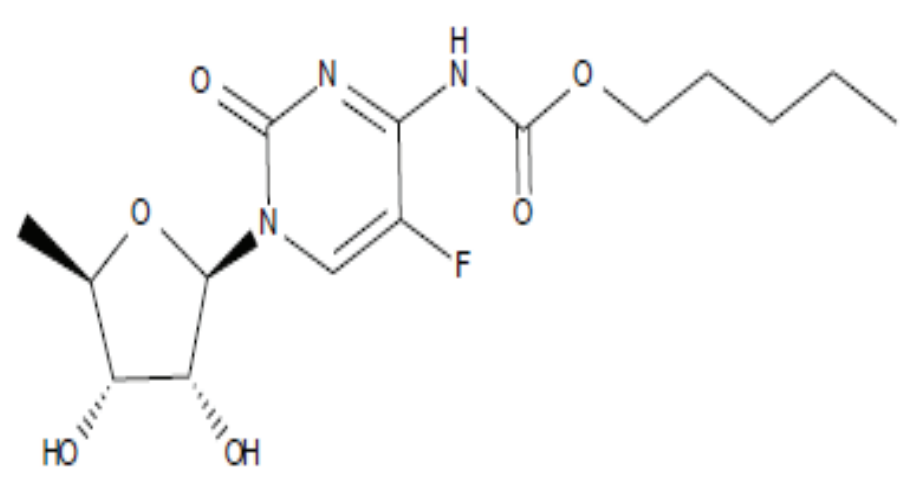

Figure 1. Structure of Capecitabine

\section{Preparation of Standard Stock Solution}

A $60 \mathrm{mg}$ of capecitabine pure drug was dissolved in $60 \mathrm{ml}$ of mobile phase. It was then sonicated for 5 minutes and made up the volume to $100 \mathrm{ml}$. This solution is then degassed using sonicator for 30 minutes $(600 \mu \mathrm{g} / \mathrm{ml})$.

\section{Preparation of Sample}

Twenty tablets were weighted. Average weight of tablets was calculated. All tablets were crushed to powder form. A quantity of powder containing about $60 \mathrm{mg}$ of capecitabine was weighed accurately and transferred into $100 \mathrm{ml}$ volumetric flask. About $70 \mathrm{ml}$ of mobile phase was added and sonicated for 15 minutes. It was then cooled to room temperature and volume was made up to $100 \mathrm{ml}$. It was then passed through PVDF $0.45 \mu \mathrm{m}$ filter, and used thereafter $(600 \mu \mathrm{g} / \mathrm{ml})$. Appropriate aliquot was taken, diluted using mobile phase and analyzed by the proposed method.

\section{Development of Calibration Curves/ Linearity}

Calibration curve for capecitabine standard drug was plotted by preparing sample solution by diluting standard solution of capecitabine in mobile phase. From this stock solution, solutions of $50,70,90,110,130$ and $150 \mu \mathrm{g} / \mathrm{ml}$ concentration were prepared. Analysis of these solutions was carried out using chromatographic conditions, specified in Table 1.

\section{Assay of Tablet}

From the triturate of 20 tablets, an amount equivalent to $60 \mathrm{mg}$ of capecitabine was weighed and dissolved in $60 \mathrm{ml}$ of mobile phase. It was then sonicated for 10 minutes. The solution was filtered through $0.45 \mu$ PVDF syringe filter and then final volume of the solution was made up to $100 \mathrm{ml}$ with mobile phase. Appropriate aliquot was taken, diluted using mobile phase and analyzed by the proposed method. Capecitabine tablets contain NLT $97.0 \%$ and NMT $102.0 \%$ of the labeled amount of capecitabine $\left(\mathrm{C}_{15} \mathrm{H}_{22} \mathrm{FN}_{3} \mathrm{O}_{6}\right)$ (Table 2).

\section{Method Validation}

Methods validation is the process of demonstrating that analytical procedures are suitable for their intended use. Following aspects were covered during validation of developed method as per ICH guidelines [17].

\section{Accuracy}

Accuracy expresses the closeness of agreement between theoretical and practical value. The average result of mean for each level should be within $98-102 \%$ and relative standard variation should not be more than $2 \%$. The accuracy study

Table 2. Assay and precision study of capecitabine tablet

\begin{tabular}{|c|c|c|c|c|c|}
\hline \multirow[t]{2}{*}{ Sr. no. } & \multirow[t]{2}{*}{ Sample } & \multicolumn{2}{|c|}{ Inter day } & \multicolumn{2}{|c|}{ Intra day } \\
\hline & & Area & $\begin{array}{c}\text { Capecitabine } \\
(\%)\end{array}$ & Area & $\begin{array}{c}\text { Capecitabine } \\
(\%)\end{array}$ \\
\hline 1. & Precision Set 1 & 9435871 & 96.9 & 9440865 & 97.03 \\
\hline 2. & Precision Set 2 & 9478159 & 98.3 & 9450325 & 97.6 \\
\hline 3. & Precision Set 3 & 9460601 & 98.0 & 9487421 & 98.6 \\
\hline 4. & Precision Set 4 & 9510168 & 97.6 & 9450627 & 97.3 \\
\hline 5. & Precision Set 5 & 9457224 & 97.8 & 9457324 & 97.8 \\
\hline \multirow[t]{4}{*}{6.} & Precision Set 6 & 9434868 & 97.5 & 9506984 & 97.4 \\
\hline & & Average & 97.68 & Average & 97.87 \\
\hline & & Std. Dev. & 0.48 & Std. Dev. & 0.47 \\
\hline & & \% RSD & 0.49 & \% RSD & 0.48 \\
\hline
\end{tabular}

Std. Dev. is standard deviation and \% RSD is \% relative standard deviation. 
Table 3. Accuracy study of capecitabine tablet

\begin{tabular}{|c|c|c|c|c|c|}
\hline Sr. no. & Sample Identity & Amt. added in mg & Avg. Area & $\begin{array}{c}\text { Amount Recovered } \\
(\mathrm{mg})\end{array}$ & $\begin{array}{c}\text { Recovery } \\
(\%)\end{array}$ \\
\hline 1. & Accuracy-50\% & 30.62 & 5208950 & 30.71 & 101.22 \\
\hline 2. & Accuracy-100\% & 61.02 & 10326070 & 60.89 & 100.69 \\
\hline \multirow[t]{4}{*}{3.} & Accuracy-150\% & 87.16 & 14365781 & 84.70 & 98.07 \\
\hline & & & & Average & 99.99 \\
\hline & & & & Std. Dev. & 1.69 \\
\hline & & & & $\%$ RSD & 1.69 \\
\hline
\end{tabular}

Amt. is amount, Avg. is average, Std. Dev. is standard deviation and \% RSD is \% relative standard deviation. For average area (n-=3).

was carried out by recovery study. The recovery study was carried out by spiking pure capecitabine in marketed formulation sample for analysis and determining amount of pure drug recovered from same. The results of accuracy study are reported in Table 3.

\section{Precision}

The precision reflects closeness of agreement between a series of results determined by analyzing multiple samples of single analyte. According to ICH guidelines, precision can be determined by repeatability and intermediate precision study. Repeatability expresses degree of obtaining same result after analysis of sample over a short period of time. Intermediate precision deals with study of within-laboratory variations like different days. The results of precision study are reported in Table 2.

\section{Specificity}

Specificity reflects ability to quantify unequivocally the analyte in the presence of components like impurities, degradants, and matrix, which may be expected to be present. Influence of such interfering components on retention time of capecitabine can be assessed by forced degradation studies. These were carried out by analysis sample after exposing it to 0.1 M hydrochloric acid (acidic), 0.1 M sodium hydroxide (basic) and 10\% hydrogen peroxide (oxidative) solution. The results of specificity study are reported in Table 4.

\section{Robustness}

Robustness indicates capacity of method to remain unaffected due to small but deliberate variations in method parameters like flow rate, wavelength of analysis, and or temperature of analysis etc. The results of robustness study are reported in Table 5.

\section{Linearity and Range}

Linearity indicates obtaining test results which were directly proportional to the concentration of analyte in the sample within range specified. Solutions of $10,30,50,70,90,110$, $130,150,170,190$ and $210 \mu \mathrm{g} / \mathrm{ml}$ concentration were injected.

Table 4. Specificity study of capecitabine tablet

\begin{tabular}{|c|c|c|c|c|}
\hline Sr. no. & Sample & Name & Area & $\begin{array}{c}\text { Capecitabine } \\
(\%)\end{array}$ \\
\hline 1. & Control & Capecitabine & 9866577 & 101.4 \\
\hline \multirow[t]{2}{*}{2.} & $0.1 \mathrm{M} \mathrm{HCl}$ & Degradants & 2184640 & 32.5 \\
\hline & & Capecitabine & 6503440 & 67.5 \\
\hline \multirow[t]{2}{*}{3.} & $0.1 \mathrm{M} \mathrm{NaOH}$ & Degradants & 962765 & 14.6 \\
\hline & & Capecitabine & 8245257 & 85.4 \\
\hline \multirow[t]{2}{*}{4.} & $10 \% \mathrm{H}_{2} \mathrm{O}_{2}$ & Degradants & 408846 & 7.16 \\
\hline & & Capecitabine & 9072404 & 93.1 \\
\hline
\end{tabular}

$\mathrm{HCl}$ is hydrochloric acid, $\mathrm{NaOH}$ is sodium hydroxide, $\mathrm{H}_{2} \mathrm{O}_{2}$ is hydrogen peroxide and $0.1 \mathrm{M}$ means 0.1 molar. 
The method was found linear in concentration range of 50 to $150 \mu \mathrm{g} / \mathrm{ml}$.

The range is an interval between upper and lower concentration of the analyte in the sample where method was found linear. Linearity and range study was carried out together. The results of linearity and range study are reported in Table 6.

\section{System Suitability Testing}

System suitability testing is an integral part of many analytical procedures. The tests are based on the concept that the equipment, electronics, analytical operations and samples to be analyzed constitute an integral system that can be evaluated as such. System suitability test parameters to be established for a procedure depend on the type of procedure being validated. The results of system suitability studies are reported in Table 7 .

\section{RESULT AND DISCUSSION}

Capecitabine is an effective anti-cancer agent used in the treatment of metastatic breast and colorectal cancers and is a prodrug, that is enzymatically converted to 5-fluorouracil. The quantitative estimation of capecitabine is possible by spectroscopic and chromatographic methods as reported. But most of method required buffer solution for chromatographic elution [12]. Whereas few method made use of gradient elution for same [10-11]. Hence it becomes necessary to develop simple chromatographic method with isocratic elution, without buffer solution as mobile phase component. In this method, it has been achieved by developing and validating simple, accurate, precise, sensitive and selective method for quantification of capecitabine.

The chromatographic conditions were optimized on trial and error method. The wavelength of analysis as $304 \mathrm{~nm}$ was finalized by analyzing $10 \mu \mathrm{g} / \mathrm{ml}$ solution of capecitabine on UV-Visible spectrophotometer. The capecitabine is an

Table 5. Robustness study of capecitabine tablet

\begin{tabular}{|c|c|c|c|c|c|c|c|}
\hline \multirow[t]{2}{*}{ Sr. No. } & \multirow[t]{2}{*}{ Parameter } & \multicolumn{3}{|c|}{ Area } & \multirow[t]{2}{*}{ Avg. Capecitabine (\%) } & \multirow[t]{2}{*}{ Std. Dev. } & \multirow[t]{2}{*}{ \% RSD } \\
\hline & & Set I & Set II & Set III & & & \\
\hline 1. & $\begin{array}{l}\text { High flow } \\
(1.1 \mathrm{ml} / \mathrm{min})\end{array}$ & 9128302 & 9115255 & 9083072 & 98.20 & 0.26 & 0.26 \\
\hline 2. & $\begin{array}{c}\text { Low flow } \\
(0.9 \mathrm{ml} / \mathrm{min})\end{array}$ & 10821038 & 10817468 & 10825702 & 98.23 & 0.18 & 0.19 \\
\hline 3. & $\begin{array}{l}\text { High temp. } \\
\quad\left(45^{\circ} \mathrm{C}\right)\end{array}$ & 9714497 & 9712398 & 9702982 & 99.24 & 0.41 & 0.41 \\
\hline 4. & $\begin{array}{l}\text { Low temp. } \\
\left(35^{\circ} \mathrm{C}\right)\end{array}$ & 9699920 & 9710011 & 9693852 & 99.38 & 0.66 & 0.66 \\
\hline
\end{tabular}

Std. Dev. is standard deviation and \% RSD is \% relative standard deviation. For Avg. of Capecitabine \% $(n=3)$.

Table 6. Linearity and range study of capecitabine tablet

\begin{tabular}{|c|c|c|}
\hline Sr. no. & Concentration (\%) & Area \\
\hline 1. & 50 & 5304893 \\
\hline 2. & 70 & 83005483 \\
\hline 3. & 90 & 9235318 \\
\hline 4. & 110 & 10155951 \\
\hline 5. & 130 & 11321934 \\
\hline \multirow[t]{4}{*}{6.} & 150 & 14950420 \\
\hline & Slope & 16227 \\
\hline & Intercept & 527842 \\
\hline & Correlation coefficient & 0.99958 \\
\hline
\end{tabular}


Table 7. System suitability parameters

\begin{tabular}{lc}
\hline Parameters & Limits (Units) \\
\hline Tailing factor & $<1.25$ \\
Therotical plates & $>4000$ \\
Retention time & 6.4 minute \\
Standard deviation & $<1.0 \%$ \\
\% RSD & $<2.0 \%$ \\
Correlation coefficient & $<0.9977$ \\
\hline
\end{tabular}

Table 8. Summary of results

\begin{tabular}{llc}
\hline Parameter & \multicolumn{1}{c}{$\begin{array}{c}\text { Acceptance criteria } \\
\text { (Units) }\end{array}$} & $\begin{array}{c}\text { Result obtained } \\
\text { (Units) }\end{array}$ \\
\hline Precision & $\%$ RSD $<1.5 \%$ & $0.49 \%$ \\
Accuracy & $\%$ RSD $<2 \%$ & $1.69 \%$ \\
Linearity & Correlation coefficient $>0.9999$ & 0.99958 \\
Robustness: High flow & & $0.26 \%$ \\
Robustness: Low flow & \% RSD $<1.5 \%$ & $0.19 \%$ \\
Robustness: High pH & & $0.41 \%$ \\
Robustness: Low pH & & $0.66 \%$ \\
Specificity & Forced Degradation & In $0.1 \mathrm{M} \mathrm{HCl} 32.5 \%$ degraded \\
Range & Normally accepted range $70-130 \%$ & $90-110 \%$
\end{tabular}

organic entity hence it will have assumed that it will be eluted on bonded stationary phases like C8 or C18. Hence, reverse phase chromatographic analysis has been proposed. The it has been observed that capecitabine was eluted on Inertsil ODS, $(250 \times 4.6 \mathrm{~mm}, 5 \mu \mathrm{m}) \mathrm{C} 18$ column with good retention parameters. The selectin of mobile phase was carried out by changing composition of methanol and acetonitrile over wide range. But tailing of capecitabine peak was observed. Hence $0.1 \%$ acetic acid solution was used along with methanol and acetonitrile. Finally, capecitabine was eluted with good retention parameters using $0.1 \%$ acetic acid, methanol and acetonitrile $(5: 60: 5, v / v)$, Inertsil ODS, $(250 \times 4.6 \mathrm{~mm}, 5 \mu \mathrm{m})$ C18 column, $1 \mathrm{ml} / \mathrm{min}$ flow rate and $304 \mathrm{~nm}$ as wavelength of analysis. The capecitabine has shown well resolved peak at retention time 6.4 minute (Figure 2).

The developed method was applied for quantification of capecitabine in marketed formulation. The results of assay of capecitabine tables were found to within limits as shown in Table 2. The capecitabine tablets were found to contain
NLT 97\% and NMT 103\% capecitabine. The developed method was validated using ICH Q2B guidelines. Nearly all validation parameters were studied for developed method. The capecitabine was found linear in concentration range of $50-150 \mu \mathrm{g} / \mathrm{ml}$ with correlation coefficient value, 0.9977 . The accuracy study was carried out by recovery study whereby recovering pure capecitabine from tablet solution. The precision study was carried out by analyzing tablet solution with change in time of analysis (inter day and intraday). The robustness was studied by flow rate and temperature of analysis variations. The specificity study was carried out by stability study i.e. by forced degradation of capecitabine in acidic, alkaline and oxidative conditions. The retention time of capecitabine was not changed in presence of its degradation products, confirming specificity of method. The system suitability parameters like tailing factor, therotical plates, retention time etc. were found within limits, thereby confirming least influence of instrumental error contributing factors. All the results of analysis and validation are summarized in Table 8. 


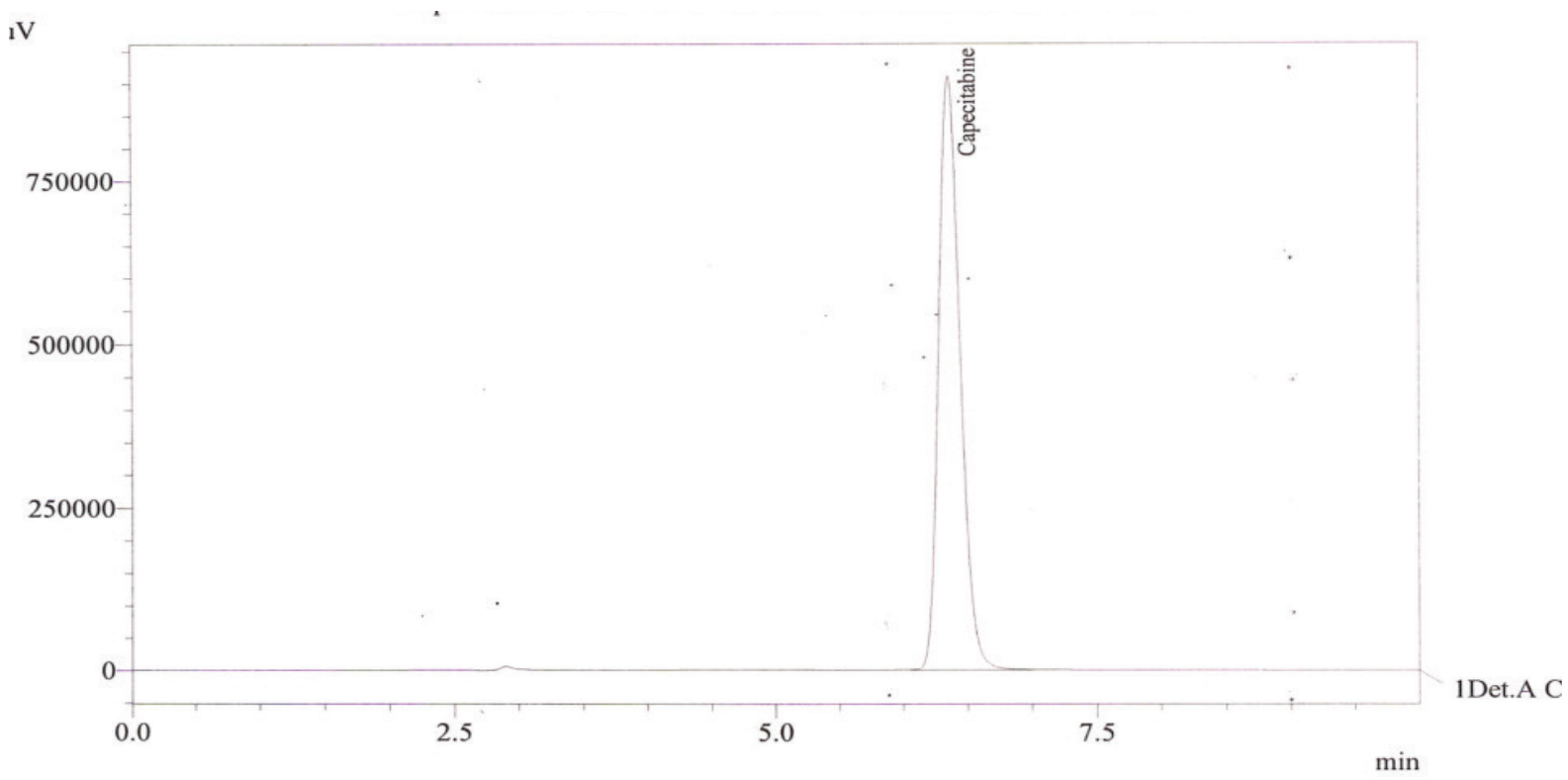

Figure 2. Chromatogram of Standard Drug

Retention time for Capecitabine standard is at 6.4 minute.

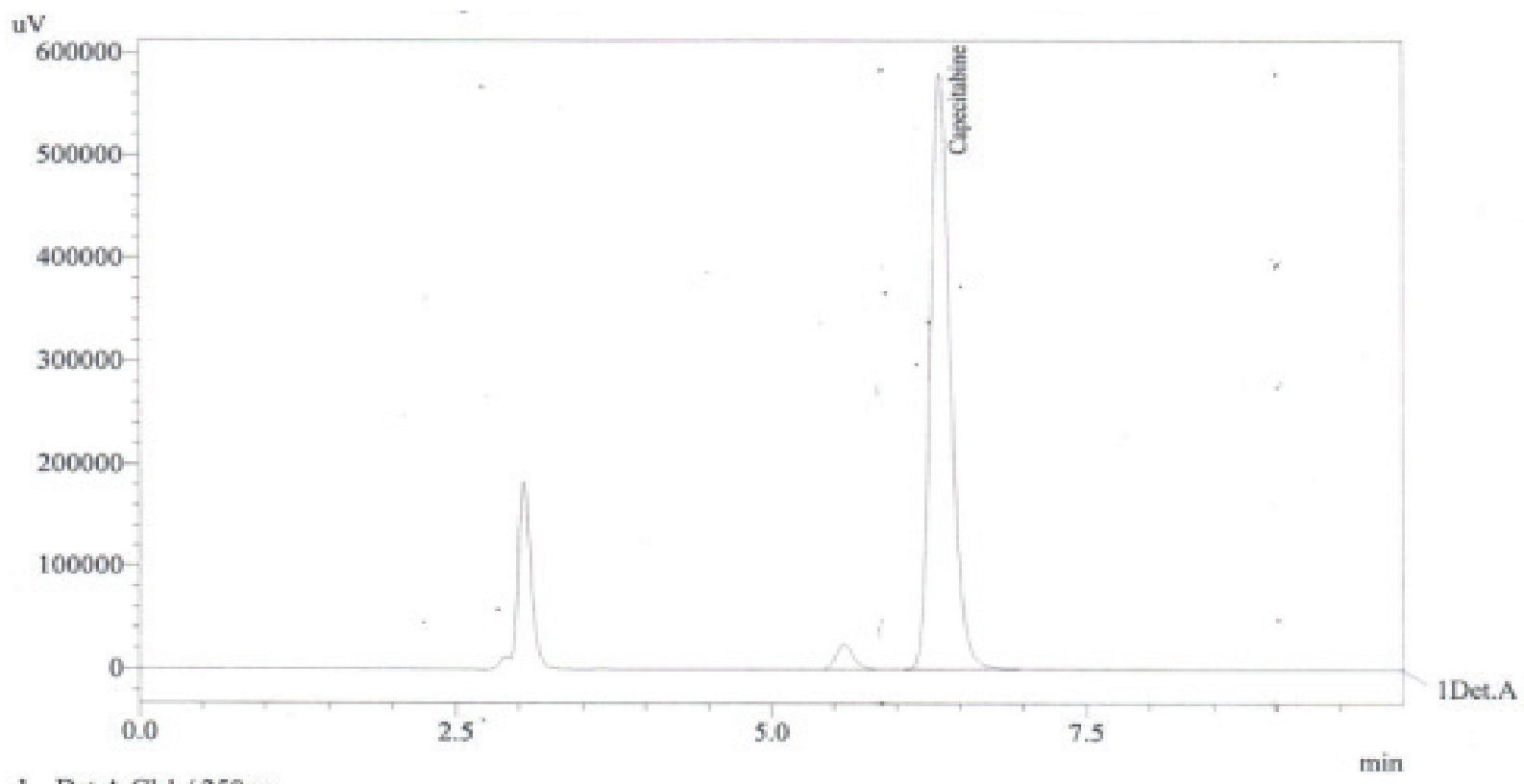

1 Det_A Ch1 / 250nm

Figure 3. Chromatogram for specificity in $0.1 \mathrm{M} \mathrm{HCl}$

Peak for Degredant is found at 3.3 minute and for Capecitabine it is at 6.38 minute. 


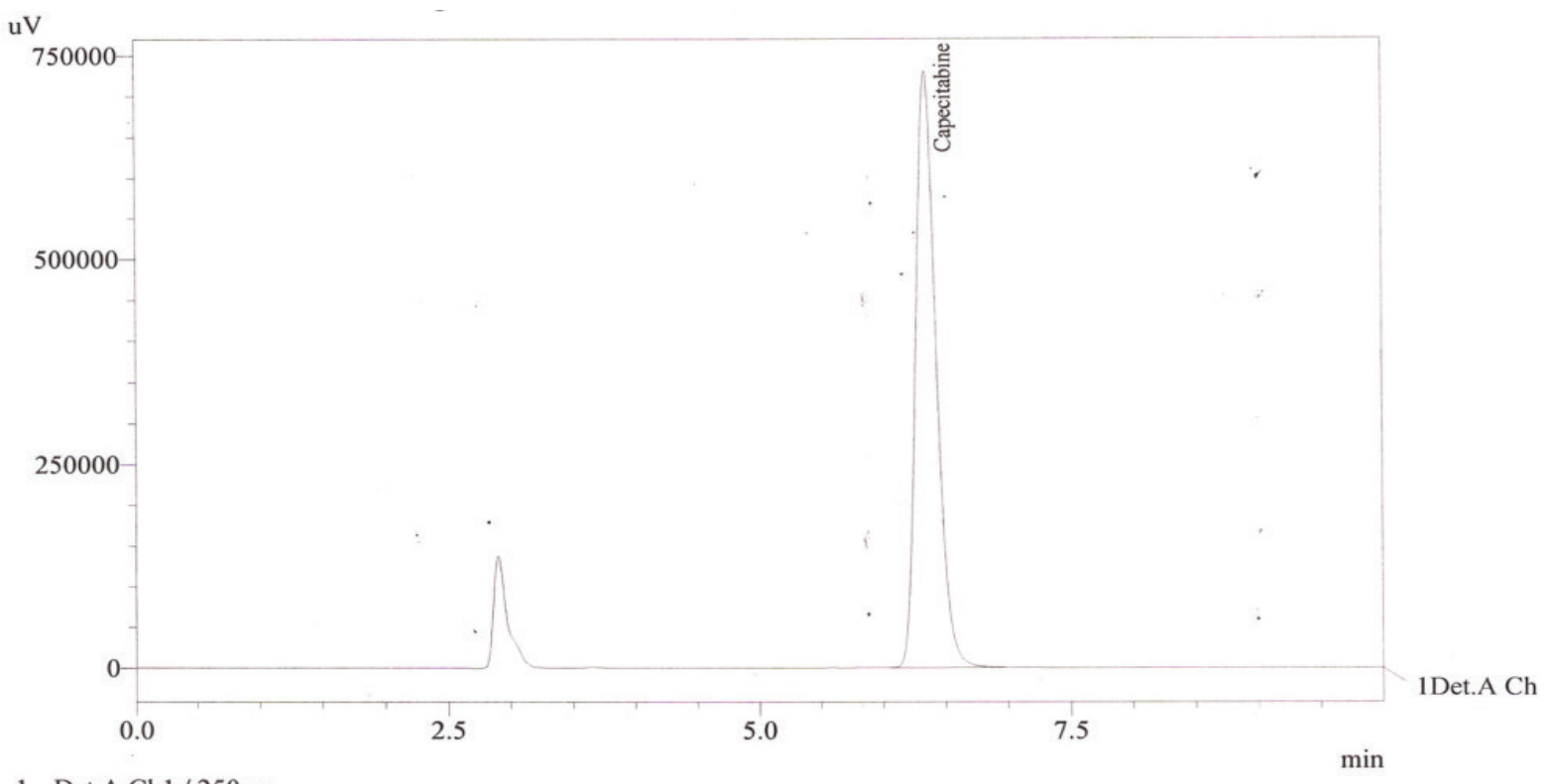

1 Det.A Ch1 / 250nm

Figure 4. Chromatogram for specificity in $0.1 \mathrm{M} \mathrm{NaOH}$

Peak for Degredant is found at 2.95 minute and for Capecitabine it is at 6.38 minute.

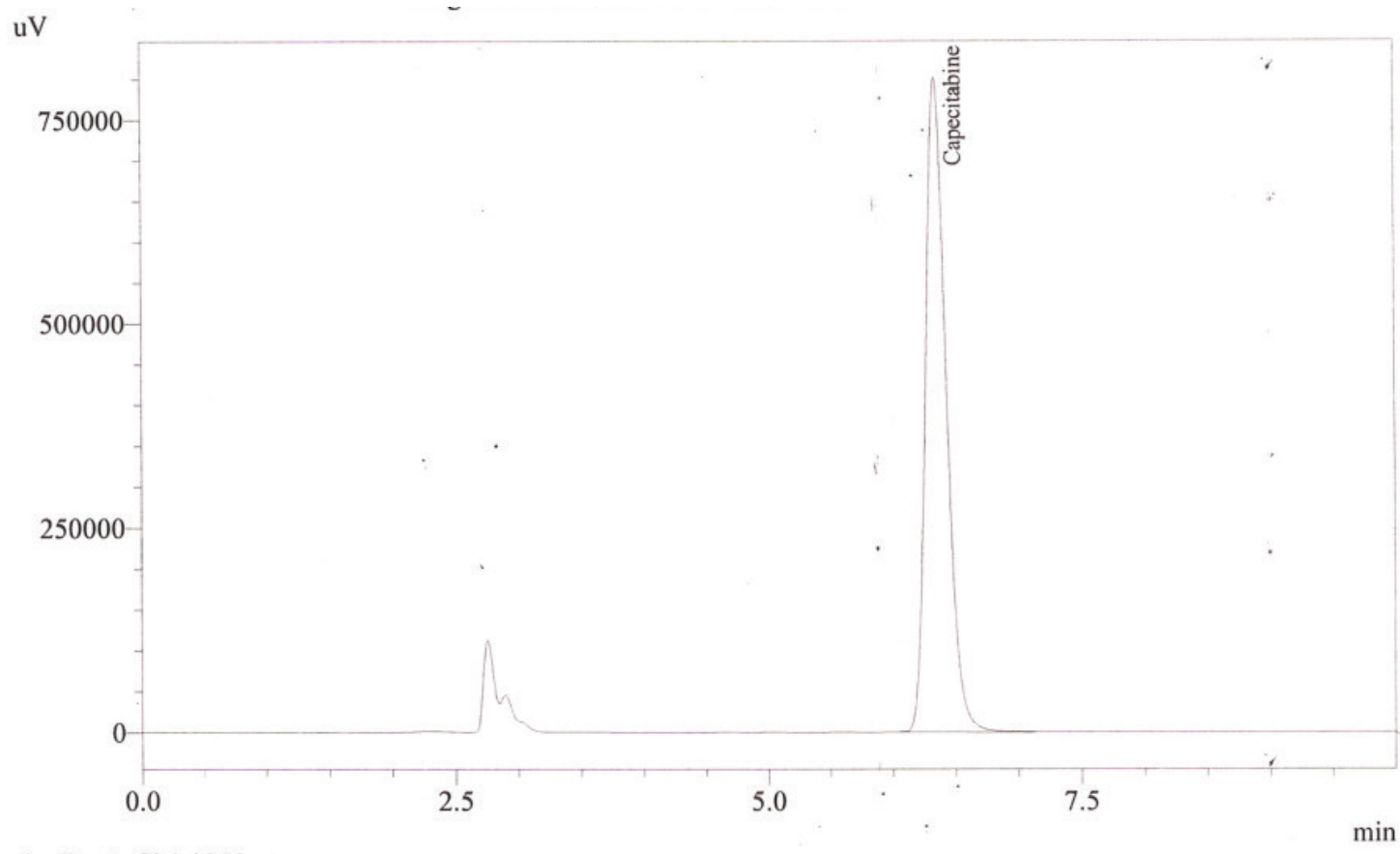

1 Det.A Chl / 250nm

Figure 5. Chromatogram for specificity in $10 \% \mathrm{H}_{2} \mathrm{O}_{2}$

Peak for Degredant is found at 2.7 minute and for Capecitabine it is at 6.38 minute. 


\section{CONCLUSION}

From results of analysis and validation, it can be concluded that developed method is simple, accurate, precise, sensitive, and selective for quantification of capecitabine from its marketed formulations and it can be used for pharmacokinetic and biopharmaceutical studies with slight modification in optimized chromatographic conditions.

\section{REFERENCES}

1. The Merck Index, 6281, 13 ${ }^{\text {th }}$ edition. Merck research Laboratories. Merck \& Co., Inc., USA. 2001, pp 1154.

2. United States Pharmacopoeia 32-National Formulary 27. 2009, pp 2148-2149.

3. Guichard SM, Mayer I, Jodrell DI. Simultaneous determination of capecitabine and its metabolites by HPLC and mass spectrometry for preclinical and clinical studies J Chromatogr B 2005; 826:232-7.

4. Vermes A, Guchelaar HJ, Dankert J. Flucytosine: a review of its pharmacology, clinical indications, pharmacokinetics, toxicity and drug interactions. J Antimicrob Chemother 2000;46:1719.

5. Dooley M, Goa KL. Capecitabine. Drugs 1999; 58: 69-76.

6. Twelves C, Glynne-Jones R, Cassidy J, Schüller J, Goggin T, Roos B, Banken L, Utoh M, Weidekamm E, Reigner B. Effect of hepatic dysfunction due to liver metastases on the pharmacokinetics of Capecitabine and its metabolites. Clin Cancer Rese 1999; 5: 1696-702.

7. Capecitabine. Available at ; https://pubchem.ncbi.nlm.nih. gov/compound/60953.

8. Hassanlou S, Rajabi M, Shahrasbi AA, Afshar M. Development and validation of an ecofriendly HPLC-UV method for determination of capecitabine in human plasma: Application to pharmacokinetic studies. S Afr J Chem 2016; 69: 174-9.

9. Deng P, Ji C, Dai X, Zhong D, Ding L, Chen X. Simultaneous determination of capecitabine and its three nucleoside metabolites in human plasma by high performance liquid chromatography-tandem mass spectrometry. J Chromatogr B Analyt Technol Biomed Life Sci 2015; 989: 71-79.

10. Piórkowska E, Kaza M, Fitatiuk J, Szlaska I, Pawiński T, Rudzki PJ. Rapid and simplified HPLC-UV method with online wavelengths switching for determination of capecitabine in human plasma. Pharmazie 2014; 69: 500-5.
11. Deenen MJ, Rosing H, Hillebrand MJ, Schellens JHM, Beijnen JH. Quantitative determination of capecitabine and its six metabolites in human plasma using liquid chromatography coupled to electrospray tandem mass spectrometry. J Chromatogr B Analyt Technol Biomed Life Sci 2013; 913914:30-40.

12. Montange, Berard M, Demarchi M, Muret P, Piédoux S, Kantelip JP, Royer B. An APCI LC-MS/MS method for routine determination of capecitabine and its metabolites in human plasma. J Mass Spectrom 2010; 45: 670-7.

13. Vainchtein LD, Rosing H, Schellens JHM, Beijnen JH. A new, validated HPLC-MS/MS method for the simultaneous determination of the anti-cancer agent capecitabine and its metabolites: 5'-deoxy-5- fluorocytidine, 5'-deoxy-5fluorouridine, 5-fluorouracil and 5-fluorodihydrouracil, in human plasma. Biomed Chromatogr 2010; 24: 374-86.

14. Švobaite R, Solassol I, Pin uet F, Mazard T, Ivanauskas L, Ychou M, Ressolle FMM. A liquid chromatography-mass spectrometry method for the simultaneous determination of capecitabine, 5'-deoxy-5-fluorocytidine, 5'-deoxy-5fluorouridine, 5-fluorouracil, and 5-fluorodihydrouracil in human plasma. J Liq Chromatogr Relat Technol 2010; 33: 1705-19.

15. Licea-Perez H, Wang S, Bowen C. Development of a sensitive and selective LC-MS/MS method for the determination of a-fluoro- $\beta$-alanine, 5-fluorouracil and capecitabine in human plasma. J Chromatogr B Analyt Technol Biomed Life Sci 2009; 877: 1040-6.

16. Singhal P, Shah PA, Shah JV, Sharma P, Shrivastav PS. Determination of capecitabine-an anticancer drug in dried blood spot by LC-ESI-MS/MS. Int J Pharm Pharm Sci 2015; 7: 238-45.

17. Ravisankar P, Devala Rao G, Naveen Kumar M, Krishna Chaitanya M. An improved RP-HPLC method for the quantitative determination of capecitabine in bulk and pharmaceutical tablet dosage form. Pharm Lett 2013; 5: 24960.

18. Kishore M, Jayaprakash $\mathrm{M}$, Vijayabhaskarareddy $\mathrm{T}$. Spectrophotometric determination of capecitabine in pharmaceutical formulations. Int J ChemTech Res 2011; 3: 639.

19. Guichard SM, Mayer I, Jodrell DI. Simultaneous determination of capecitabine and its metabolites by HPLC and mass spectrometry for preclinical and clinical studies. J Chromatogr B Analyt Technol Biomed Life Sci 2005; 826: 232-7. 